\title{
Artículos
}

\section{Los ricos más ricos de El Salvador}

\author{
M. Dolores Albiac
}

(En contraposición a

"los tristes más tristes del mundo", del Poeme de amor de Roque Dalton.)

\section{Resumen}

El primer dilema de este trabajo fue determinar si en la élite económica existen o no cambios, si son los de siempre o si hay nuevas caras, apellidos y capitales. "Más que cambiar las personas, cambiaron los capitales"; "son los mismos con pequeños cambios en quién sube o baja"; "hay algo de cambio generacional, de fusiones y particiones por matrimonios o herencias...". En todo caso, ni las guerras fronterizas o civiles ni un siglo de drásticos cambios del mercado internacional del que dependen, han alterado esa característica esencial de esta economía: la alta concentración.

\section{Introducción}

Hace menos de una década, Roberto Mathies Hill y su padre, Roberto Mathies Regalado, se sentaban junto a otros tres Robertos de rancio apellido a comentar los destinos del país, cuya guerra se prolongaba casi una década. Conocidos en círculos del poder como los "cuatro Bobys", eran la créme de la créme al concentrar en sus apellidos, o los de sus esposas - por delegación del grupo familiar-, las mayores fortunas del país. Jóvenes y dinámicos, casados con otras herederas de renombre, que crecieron y estudiaron en Estados Unidos, al frente del negocio familiar, con buenos modales y bilingües, eran una élite distinta de los adinerados tradicionales, proclives a las soluciones simples y expeditas, poco instruidos, que viajaban poco y dirigían el país cual finca.

En su rancho playero de la Costa del Sol citaron a los presidentes de la Corte Suprema de Justicia, de la Asamblea Legislativa, del partido conservador... en fin, a la élite política para, entre otras cosas, analizar el declive del ejecutivo, encabezado por un demócrata cristiano mortalmente enfermo y cuyo partido se desfondaba. Además, al final de su vida y de la presidencia, intentaba atar unas conversaciones con la guerrilla, percibidas como traición' .

1. Diversas fuentes describieron entonces a esta corresponsal las inquietudes de este grupo, usual en otros países para repasar la actualidad, conceder o retirar apoyos y propiciar coyunturas. 
También asistía la joven promesa, Alfredo Cristiani, quien se curtía como diputado de Alianza Republicana Nacionalista (ARENA), aunque pasaba desapercibido por su estilo y la preponderancia de "el" líder histórico, Roberto D'Aubuisson. Desconocido en los círculos públicos ${ }^{2}$, no estaba allí tanto en calidad de político como de alevín de esa renovada élite económica que, a través de él y por primera vez en muchos años de historia, hacía pinitos en la política, sin intermediarios.

A diez años de ese soleado día, "Robertillo" - como lo llama la familia sanguínea y partidaria- está en la cárcel y su padre está huyendo del país desde hace meses, a raíz del escándalo financiero ocurrido en sus empresas que dejó un agujero de 250 millones de dólares 3 . Un lío que frustró sus aspiraciones presidenciales desde el trampolín de jefe del sector económico de ARENA. A su vez, Cristiani, tras pasar a la historia como el presidente que firmó una paz negociada con la guerrilla, que desmilitarizó el país, pero dejó intacta la economia, regresó al frente del partido, tras pasar algunos años opacado y, sobre todo, con una de las principales fortunas del país.

El primer dilema de este trabajo fue determinar si en la élite económica existen o no cambios, si son los de siempre o si hay nuevas caras, apellidos y capitales. Más específicamente, si se limita a una renovación generacional o a factores como la guerra, las privatizaciones o la globalización las que han alterado ese 1 por ciento de la población, 116 propietarios que, a finales de los setenta, absorbían el 35 por ciento del ingreso nacional, cuyas ganancias declaradas eran de, por lo menos, 20 millones colones al año, es decir, 6700 veces el ingreso de un trabajador ${ }^{4}-19$ veces más es la actual media latinoamericana, el continente con mayor desigualdad en el mundo, que tiene una media de ocho ${ }^{5}$ -

Casi dos décadas después, unos 3 millones y medio de salvadoreños viven con un dólar al día
(700 mil hogares ${ }^{6}$ y de ellos, cien mil familias con 1 colón diario (0.1 dólar). En el otro extremo, 518 familias declaran quen ganan al mes por lo menos 10000 dólares, y sus ingresos son casi el doble de lo que percibe el estrato inmediatamente inferior. Los tres niveles más bajos, casi un millón de personas, ingresan diez veces menos que la media nacional y los tres más altos, poco más de mil hogares, ingresan una media declarada 17 veces más alta que la nacional. Dentro de éstos y en el rango superior, los 518 hogares más ricos tienen una media 23 veces mayor que la nacional.

"Más que cambiar las personas, cambiaron los capitales", concluyó un economista. "Son los mismos con pequeños cambios en quién sube o baja", añadió un profesor. "Hay algo de cambio generacional, de fusiones y particiones por matrimonios o herencias, pero la última configuración es consecuencia de cómo se han colocado en la privatización, igual que en el pasado ocurrió otras tres veces con la sustitución de productos". En todo caso, son muy pocos y ni las guerras fronterizas o civiles, ni un siglo de drásticos cambios del mercado internacional del que dependen, han alterado esa característica esencial de esta economía: la alta concentración.

A petición de algún entrevistado, se guarda el anonimato en las citas, aunque la mayoría de las fuentes se detallan en el anexo. Sin ánimo de justificar el intrínseco miedo salvadoreño a llamar a las cosas por su nombre, es necesario recordar cómo algunos miembros de la élite económica fundaron o financiaron los paramilitares escuadrones de la muerte y cómo la guerrilla del Frente Farabundo Martí (en adelante, FMLN) utilizó, en sus secuestros de comienzos de la guerra civil (entre 1979 y 1982), las listas de hacendados. Tal vez todo ello y la improvisación que domina a la intelectualidad de este país desde que la vorágine de cambios postbélicos los rebasó, expliquen la ausencia de estudios recientes sobre la concentración del poder económico.

2. El designado como candidato era el líder empresarial Víctor Steiner, quien declinó por padecer de una enfermedad mortal.

3. Finsepro-Insepro. Ver privatización de la banca.

4. Manuel Sevilla, "Visión global sobre la concentración económica en El Salvador", Boletín de Ciencias Económicas, 1984, p. 156.

5. Programa de Naciones Unidas para el Desarrollo, Informe sobre desarrollo humano 1997.

6. Encuesta de hogares 1996. Dirección General de Estadística y Censos. 


\section{Prólogo a la edición de ECA}

Llamadas, cartas, advertencias más o menos abiertas, consejos sobre un eventual susto..., la polvareda que originó esta publicación superó lo previsible y merece comentario al abundar en la gran distancia entre lo que sucede en los centros de poder y lo que se publica, además de mostrar, cual improvisado termómetro, la poca transparencia del sistema. Las dudas sobre si valió la pena este desgaste se disiparon al presentar el libro ante un abarrotado auditorio - la mitad, entusiastas estudiantes, que quieren mirar su país sin los prejuicios del pasado; la otra mitad, una mezcla de gentes de muy diversa edad, condición y filiación, interesados unos, enviados otros-.

\section{POR QUÉ ESCRIBIMOS}

\section{Roque Dalton}

Uno hace versos y ama

Uno se va a morir,

la extraña risa de los niños, mañana,

el subsuelo del hombre un año,

que en ciudades ácidas disfraza la leyenda

un mes sin pétalos dormidos;

la instauración de la alegría

disperso va a quedar bajo la tierra

que profetiza el humo de las fábricas.

y vendrán nuevos hombres

pidiendo panoramas.

Uno tiene en sus manos un pequeño país,

Preguntaran qué fuimos,

Horribles fechas,

quienes con llamas puras les antecedieron

muertos como cuchillos exigentes (...)

a quienes maldecir con el recuerdo.

Bien.

Eso hacemos:

custodiamos para ellos el tiempo que nos toca.

Con este poema inicié la presentación y quise responder a las variadas interpretaciones sobre mis propósitos. En esencia, los comentarios críticos y las presiones provinieron de empresarios molestos: los mencionados, porque se analiza el origen y evolución de sus fortunas, y los otros, por no ser mencionados. Alguno se refirió a la vulnerabilidad frente al secuestro, un grave asunto que no depende de estudios de este tipo. Un disimulado deno-

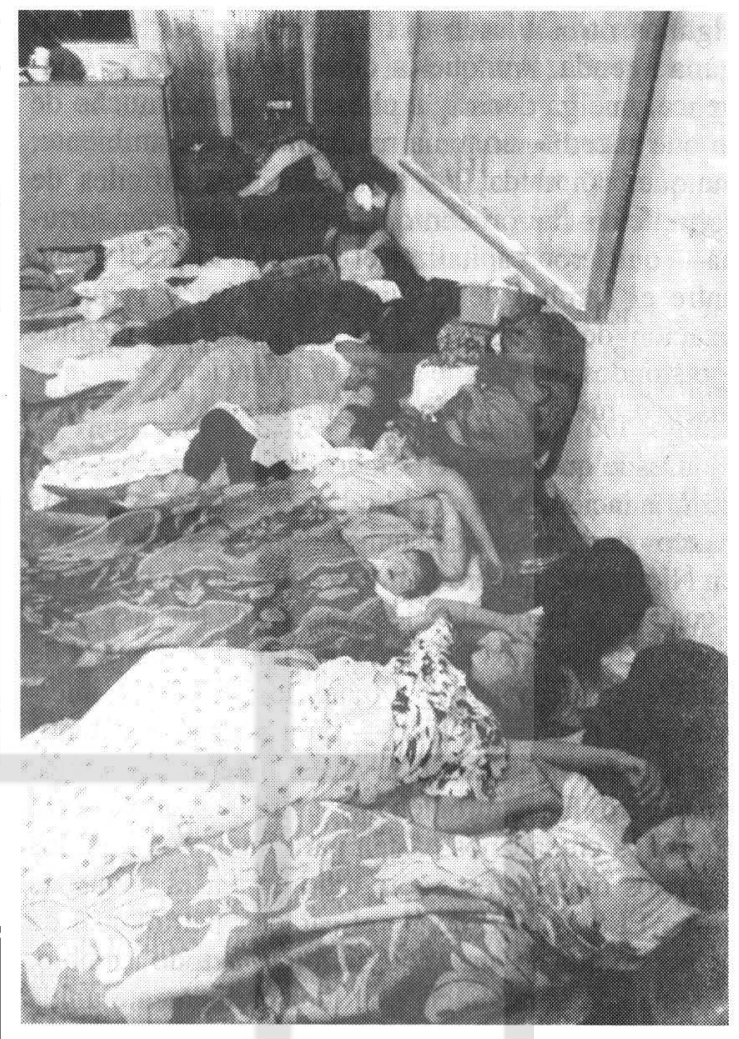

minador común fue que analizar la distribución es una forma de "odio de clase". ¡Curioso que esta lógica no se aplique cuando se estudia la pobreza! ¿Por qué sí con la riqueza? Además, a nadie se le ocurre ni el odio de clase ni el secuestro cuando la revista Forbes clasifica cada año las mayores fortunas.

Elaborada en febrero de 1998, para el anuario económico Die Macht und die Herrlichkeit, esta investigación fue financiada por la Fundación Heinrich Boll - del partido de los verdes de Alemania-, que decidió publicarla en castellano cinco meses después, como aportación al latente debate sobre el modelo económico en curso, un asunto intacto en las reformas de paz acordadas. Por la premura de los editores, el trabajo se publicó con errores, utilizados también para descalificar su validez. Si bien nada disculpa la imperfección, las erratas eran de forma y no alteraron el transfondo, que era y es el meollo del asunto.

Aunque por entonces faltaba un año para las elecciones presidenciales, las aguas comenzaron a enturbiarse en los principales partidos: los conservadores de ARENA y la izquierda del FMLN y 
algunos otros vieron el trabajo como parte de alguna agenda. Aunque la clase política no se convence, huelga decir que el escrito, como mucho de lo que sucedía, no tenía relación con ese ambiente; aunque, sin duda, las tensiones más difíciles de sobrellevar fueron con quienes - pocos, por fortuna- quisieron capitalizar el revuelo. El paralelismo entre el cambio de la élite económica y la privatización de la banca, y en particular los inéditos transfondos del escándalo de la financiera FinseproInsepro, fue sin duda lo que más molestó.

Desde que terminé la investigación hace un año, otra financiera dejó en el limbo a los ahorrantes; seis bancos cerraron en Guatemala; otro fue intervenido en Nicaragua; quebró la mitad del sector bancario de Ecuador; y la devaluación de Brasil, Rusia y Asia convencieron a los más renuentes de la necesidad de establecer mecanismos a todos los niveles -internacional, regional y local- para normar y garantizar transparencia en el, a veces, hipertrófico sector financiero. Estas turbulencias y su devastador efecto sobre los ciudadanos bastan para mirar con lupa los cambios financieros, sobre todo en países pequeños como El Salvador, donde el caracter patrimonial de la economía da un sello familiar a todo cambio. Además, la democracia está indisolublemente unida a la transparencia, tanto que es un termómetro del grado de solidez de este sistema político.

El que unos, muchos, casi dos tercios, vivan en la edad media y que otros, pocos, unos cientos, vivan en el siglo XXI —con 500 años de distancia-, no es una cruda realidad a analizar cuanto antes - los estudios de la pobreza abundan, los de la riqueza brillan por su ausencia-; es que además de un siglo diferente, hay gente que pretede vivir en un mundo diferente, aunque no sé qué querrán hacer con "los otros", ese entre 60 a 70 por ciento de los centroamericanos con un escueto dólar al día.

Para el economista Carlos Glower -a quien también molestaron por atreverse a presentar este trabajo- debe haber más ricos en El Salvador. En mi humilde opinión, de momento bastaría con que los que hay asumieran global y cotidianamente un rol que vaya más allá de su grupo de interés, de una visión de Estado, de nación, de región. Como también a otro nivel y en su ámbito - menos decisivo, quizás - sería loable otro tanto de los econo- mistas, funcionarios, líderes sindicales y sociales, intelectuales, consultores y "gurus" varios. Pero eso es asunto de los propios salvadoreños.

Como dije en la presentación, en lo que a los extrajeros corresponde, la desigual distribución y cómo se agudiza levanta otras interrogantes: ¿qué enfoque dar a la cooperación con los países desarrollados - generada por un gran esfuerzo impositivo de nuestros ciudadanos- para que no sustituya la necesaria contribución del sector privado de los propios países en su desartollo?

\section{Los viejos ricos}

\subsection{Diferentes planos del poder}

Cuando, en 1993, los ministros de asuntos exteriores de la Unión Europea (UE) y de Centroamérica se reunieron en San Salvador, en ronda anual, los europeos se sorprendieron de la distancia y la frialdad del entonces presidente Cristiani. La actitud no podía explicarse sólo por la tensión de una declaración unilateral de la Unión Europea, insistiendo en la Comisión de la Verdad - una comisión internacional que investigó los crímenes de guerra en El Salvador y recomendó la inhabilitación pública de los victimarios-.

AJ hablarlo con una fuente conocedora de los entresijos del poder, comentó: "Ustedes, los europeos, a veces se despistan con estos países pequeños, pobres y perdidos. ¿Cuánto gana un ministro en tu país?". Con lápiz y papel sacó la cuenta del sueldo mensual promedio de los doce ministros de la Unión y dijo: "Cristiani ingresa eso o más en un solo día". Sin embargo, el padre de Cristiani no figuraba entre quienes poseían las principales fortunas del país en $1980^{7}$, mientras que los Regalado Dueñas eran, con mucho, los mayores rentistas.

A senso contrario, todavía se recuerda en la embajada de Estados Unidos cómo, un día, Poma solicitó una donación de dos computadoras, sin que su distante nivel de renta respecto al funcionario que lo atendió, lo ruborizara. Abundan estas anécdotas acerca de cómo la élite económica aquí, con márgenes de beneficios incomparables respecto a sus homólogos europeos y un nivel impositivo de los más bajos del continente, ha sido hasta ahora renuente a contribuir con su propio esfuerzo, ya sea

7. “Visión global de la concentración”, op. cit. 
a la guerra civil -aun convencida de disputar en ella su propia supervivencia - o al desarrollo sostenible.

\subsection{De los 114 a los 116}

A comienzos de 1960 , los mayores latifundistas eran treinta ${ }^{8}$. Cuatro - los Dueñas, Guirola, Sol y Daglio - con más de 10 mil manzanas; once con más de 5 mil y quince con más de mil. El 4.1 por ciento de los propietarios poseía el 67.28 por ciento de la tierra disponible contra un 95 por ciento que poseía apenas 32.7 por ciento. En un dato más extremo", 250539 explotaciones agrícolas no llegaban a las 10 hectáreas, constituyendo el 92.49 por ciento de las propiedades con una superficie total de 70 mil hectáreas, el 4 por ciento del área cultivable del país. Tan sólo dos décadas después - a comienzos de los ochenta - y contra la impresión general, la mayor concentración ya no se daba en el sector agricola, que se había industrializado, aunque el sector secundario en alza se estableció sobre las mismas bases de concentración.

El 1 por ciento de las empresas absorbía el 72 por ciento del excedente del sector, mientras que la mitad de las empresas, el 4 por ciento ${ }^{10}$. De 332 mil sociedades de todo tamaño, el 0.7 por ciento era grande, constituía el $\mathbf{4 5}$ por ciento de la producción, representaban sólo el 29 por ciento del empleo del sector y absorbía el 59 por ciento del excedente. Claro que la élite era casi la misma, pues la mayoría de los grandes latifundistas eran beneficiadores (procesadores de café) y así, la lista de las mayores empresas agrícolas sumaba tan sólo 18 (de las 56 627 existentes a comienzos de los ochenta).

Otro dato interesante a contrapeso de la constante concentración, es que a diferencia de los países vecinos, ya existía una clase media significativa. Así, la estructura social y económica era":

(a) Los pobres con ingresos de hasta 300 colones (34 dólares) representaban el 62 por ciento de la población, 490 mil familias, unos 2.5 millones de habitantes, y absorbían sólo el 28 por ciento del ingreso nacional. De otra forma, eran dos tercios de la población que consumían menos de un tercio de la riqueza. (b) La clase media con ingresos de entre 300 y 1000 colones (34 a 114 dólares) representaba el 32 por ciento de la población, 241 mil familias, 1200000 habitantes, quienes absorbían el 43 por ciento del ingreso. Un tercio de la población consumía menos de la mitad del ingreso.

(c) Los acomodados con ingresos superiores a los mil colones representaban el 6.2 por ciento, 48 mil familias con un total de 240 mil habitantes, que controlaban el 28.3 por ciento del ingreso nacional y 240 mil hectáreas de tierra cultivable. O sea, seis de cada cien salvadoreños absorbían casi un tercio de la riqueza y la mayor parte de la tierra.

De estos últimos, el rango más elevado era muy reducido. Según el fisco, un criterio moderado de por sí, sólo 53 declaraban rentas mayores a los 10 millones de colones ( 1140000 dólares) de entonces. En un segundo escalón, 136, con entre 5 y 10 millones (575000 a 1140000 dólares) y 1309 de más de un millón (114 000 dólares). Una distribución que, como el tamaño de las empresas - en número de trabajadores o volumen de actividad--, muestra la estratificación en el propio sector de mayores ingresos, una constante histórica de la concentración de la concentración, que continúa hoy.

\subsection{Las familias de siempre}

Sobre la base del estudio "Visión global..." ya mencionado, elaboramos un cuadro propio, agrupando a las 116 personas o grupos familiares con más del 50 por ciento de las acciones de las 1284 empresas o sociedades con capital superior a los 5 millones de colones. A simple vista se perciben algunos cambios y se acota si han crecido, si se han mantenido o si han desaparecido, en un estimado a grosso modo. Subdividimos la lista de los 116 en cinco apartados: quienes poseían acciones de empresas con capital social mayor a 400 millones de colones, donde sólo aparece la familia Regalado (440); más de $200 \mathrm{mi}-$ llones de colones, con tres grupos familiares; más de 100 millones de colones con siete familias y más de 50 millones de colones con once.

8. Roque Dalton, El Salvador. Monografía, UCA Editores, 1989 (1’ Edición 1963).

9. Censo agropecuario de 1971.

10. "Visión global", op. cit., pp. 188-189.

11. Ver el apartado 5.5 . 


\begin{tabular}{|c|c|c|c|c|}
\hline Grupo 2 & Grupo familiar & Empresas & Capital social & Tendencia ${ }^{12}$ \\
\hline \multirow{3}{*}{+200} & Meza Ayau & 104 & 238 & $\gg$ \\
\hline & Freund & 47 & 227 & $=$ \\
\hline & Hill (Argüello, Llach) & 86 & 213 & $\gg$ \\
\hline \multirow[t]{2}{*}{ Grupo 3} & De Sola & 69 & 145 & $\gg$ \\
\hline & Guirola & 52 & 122 & $\ll$ \\
\hline \multirow[t]{5}{*}{+100} & Alvarez & 95 & 167 & $<$ \\
\hline & Liebes & 41 & 101 & $>$ \\
\hline & Salaverria & 85 & 161 & $\gg$ \\
\hline & González Guerrero & 49 & 118 & $=$ \\
\hline & Simán & 52 & 135 & $\gg$ \\
\hline \multirow[t]{4}{*}{ Grupo 4} & García Prieto & 46 & 73 & $>$ \\
\hline & Dueñas & 44 & 80 & $\ll$ \\
\hline & Quiñones & 45 & 90 & $>$ \\
\hline & Baldochi-Dueñas & 22 & 72 & $\gg$ \\
\hline \multirow[t]{7}{*}{+50} & Ortiz Mancía & 33 & 94 & \\
\hline & Wright & 61 & 83 & $<$ \\
\hline & Palomo & 29 & 73 & $>$ \\
\hline & Guttfreund & 27 & 70 & $>$ \\
\hline & Mc.Entee & 19 & 58 & $>$ \\
\hline & Sol Millet & 26 & 89 & $\gg$ \\
\hline & Sarti & 5 & 52 & $=$ \\
\hline
\end{tabular}

Nota: Las cantidades están en millones de colones.

\subsection{No están todos los que son}

Mas allá de que por efectos impositivos el capital social declarado esté subvaluado, los reducidos activos de alguna familia son notables así como el no aparecimiento de otras. El caso más sorprendente son los Dueñas, quienes figuran en el tercer grupo, cuando en los sesenta encabezaban la lista de los treinta propietarios de tierra más grandes ${ }^{13}$ con casi cinco mil hectáreas (ver siguiente sección). Igualmente Dalton con sólo dos empresas y 4 millones de capital, aunque en los sesenta declaraba poseer unas 400 hectáreas y sigue siendo uno de los 25 grandes beneficadores-exportadores de café del país ${ }^{14}$.

También ocurre con los Llach que, aun siendo entonces grandes propietarios, aparecen con activos de 12 millones, en tan sólo seis empresas, en ese quinto grupo que formarían las familias con menos de 50 y más de 10 millones. Más que en estos grupos de primera línea, es precisamente entre quienes declaraban activos entre los 10 y 50 millones - el quinto grupo- donde aparece la mayor movilidad, con familias que han saltado al primer o segundo grupo como Cristiani o Poma (ver más adelante).

Entre quienes ascendieron menos rápido desde esa "quinta categoría" están los Kriete, entonces con nueve empresas y 18 millones y hoy uno de los tres grupos familiares accionistas de Taca. Es muy ilustrativo el caso de las tres familias que entonces y ahora monopolizan los medios de comunicación. En los periódicos - Dutriz (La Prensa Gráfica) y Viera Altamirano (El Diario de Hoy) - sólo aparecía en esa quinta categoría del comienzo de

12. Tendencia de los últimos veinte años; $>$ a más empresas o activos $\mathrm{y}<$, menos o el doble signo, una tendencia muy acusada a la acumulación o decrecimiento. El signo = un incremento normal de activos.

13. "El Salvador", op. cit.

14. Datos de la Asociación de Beneficiadores de Café (ABECAFE). 
los ochenta, el primero con activos de 4 millones, en once empresas, aunque sus activos actuales son mucho mayores (imprenta, radio $R C S$ ) y se extienden a la banca (Credisa). Altamirano no aparecía en ninguna.

Similar es el caso Esersky, quien entonces aparecia con 18 millones de activos, en nueve empresas (como Araujo-Esersky), en ese quinto lugar, $y$ hoy posee el monopolio de la distribución de la señal internacional deportiva $y$ de las películas estadounidenses para televisión y el casi monopolio completo audiovisual (Telecorporación Salvadoreña, canales 2, 4 y 6,) desplazando a la familia Gadala (Teleprensa, ahora accionistas minoritarios) y a Zedán (cuyo Canal 12 sobrevivió con mucha dificultad y recién vendido a Televisión Azteca).

\subsection{Matrimonios y herencias o los cambios}

Aunque lazos de sangre unían a las 53 personas con mayor capital, ya entonces alguna antigua fortuna se había divido en varias familias para evitar el fisco, por herencias o matrimonios o, por esto último, y al contrario, se habían fusionado, "porque todavía hoy, sólo se casan entre ellos o con extranjeros", aclaró una fuente. También en algunas de las más rancias familias, en los sesenta, se perdió una generación por "bohemios o sin descendencia".

Es el caso de Miguel Dueñas, casado con una Regalado - hermana de la madre de quien ahora huye, Roberto Mathies Regalado-, sin hijos. Otro tanto le ocurrió al patriarca de los Regalado, Tomás, casado con la hermana de Miguel Dueñas, quien heredó a su hermana Maruca, casada con Salvador Mathies. También el patriarca de los Meza Ayau, Rafael, en ese segundo grupo y cuya fortuna ya estaba entonces dividida entre los Sol Meza, once empresas con un capital de 22 millones, y los Meza Hill, con doce empresas y $24 \mathrm{mi}$ llones.
"En un momento decidieron 'blanquear la raza'. Los hacendados de siempre, eran todos mestizos", acotó uno de los entrevistados, al añadir que "eso explica los nuevos apellidos". La misma tesis sostuvo Eduardo Colindres ${ }^{15}$. Es el caso de Cristiani, Baldochi, Murray y Mathies, ingenieros o mecánicos -italianos los dos primeros y alemanes los últimos-, contratados para sus empresas por los Daglio, Dueñas, Meza y Regalado, respectivamente, y que, salvo el primero, que lo hizo con la hija de Buckard, se casaron con las herederas. Un caso de fusión a distinto nivel es el de los Schwartz (veintiún empresas con 48 millones) y los Vilanova, entonces con 18 millones de colones en activos de siete empresas. Entre quienes desaparecieron o decayeron están los Schmidt, Castillo, Harrison, Gadala María, Cuéllar...

\subsection{Las reformas: el primer cambio drástico}

En los años correspondientes a estas estadísticas, se fraguó un golpe de Estado reformista, encabezado por jóvenes oficiales que, aliados a los partidos opositores -Democracia Cristiana y Socialdemocracia-, formaron, en octubre de 1979, un gobierno transitorio. Dos convocatorias electorales ya habían terminado a sangre y fuego. En especial, la efervescencia revolucionaria se generalizaba por la falta de cauces legales y el desgobiemo de la dictadura del general Romero, el último de una sucesión de cincuenta años de gobiemos militares.

Además, por parecidos motivos y con menos organización política, acababa de triunfar la revolución en Nicaragua, lo que decantó o alentó al propio Estados Unidos a apoyar $\longrightarrow$ en parte fraguar- el golpe. Esto último y el rol del generalato llevó a la mayoría de la izquierda a desconfiar de un proceso al cual los convidaban a posteriori. "Ya estaban preparando la guerra", sostienen los demócrata cristianos.

La Proclama de la Junta Revolucionaria de Gobiemo de octubre de 1979, anunció una reforma

15. Eduardo Colindres, Fundamentos económicos de la burguesía salvadoreña, UCA Editores, 1977. 
agraria y la nacionalización de la banca y del comercio exterior. En realidad, la reforma agraria, aunque por la fuerza, fue desamortización y las nacionalizaciones, traspaso al Estado o estatizaciones, pues no había banca extranjera ni comercio transnacional.

\subsubsection{La reforma agraria}

En marzo de 1980, la junta promulgó los decretos 153 y 154, conocidos como "Ley Básica de la Reforma Agraria", por los que el Estado expropió fincas y haciendas de más de 500 hectáreas que "no cumplan función social", con compensación a los antiguos propietarios y transfiriendo, en régimen de copropiedad, a cooperativas y el propio Estado, representado por el recién creado Instituto de Transformación Agraria (ISTA).

Se expropiaron 238 propiedades con una extensión de unos 218 mil hectáreas, el 15 por ciento de la tierra cultivable ${ }^{16}$. Como compensación, se contempló un derecho de reserva para el propietario de 100 hectáreas, en suelos de mayor calidad, y 150 en los de menor, unas 13 mil hectáreas. El derecho de reserva fue ampliado a 245 hectáreas por la Constitución de 1983. La indemnización se determinó con base en el monto del valor promedio asignado al inmueble en la declaración de la renta del ejercicio 1976-1977, la cual sería cancelada en bonos de la reforma agraria, con un interés del 6 por ciento y redimibles a 5 y 20 años ${ }^{17}$.

La tierra cultivable, el recurso más escaso del país, la constituían 1.46 millones de hectáreas y poco más de la mitad, sólo 795 mil, estaba cultivada. La subutilización llegaba al 48 por ciento ${ }^{14}$. Una década antes, las treinta familias mencionadas representaban el 4.1 por ciento de los propietarios y controlaban el 67.28 por ciento de la tierra cultivable, de la cual el 53.1 por ciento era improducti$v^{19}$. Además del ya muy mencionado asunto del carácter contrainsurgente de esta reforma, otros dos aspectos dificultaron la aplicación de la refor- ma y hasta hoy no están muy analizados: una reforma de "arriba abajo" y el proceso afectó más a los medianos que a los grandes propietarios. Sobre lo primero, dado que la organización campesina era ilegal y estaba vinculada a una izquierda que recelaba de la reforma, los beneficiarios no fueron protagonistas, sino más bien sujetos pasivos.

"Ese día llegó el ejército con un delegado del ISTA y un asesor gringo. Nos fueron a sacar de las casas para reunirnos y dijeron que desde ese momento todo era nuestro. Al mandador lo hicieron presidente de la cooperativa; al caporal, jefe de campo; al escribiente, secretario y así... Yo, claro, quedé lo mismo: de corralero", explicó Eulogio Villalta, cuando seguía a cargo del ordeño - comalero-, en la antes hacienda "El Coyol", luego Asociación Agropecuaria Santa María ${ }^{20}$. Algunos hacendados se resistieron a tiros y un día después del decreto, se declaró el Estado de sitio y 500 técnicos del ISTA se dispersaron por el país, acompañando a la tropa ${ }^{21}$.

Respecto a la equidad de las expropiaciones e indemnizaciones, algunas familias ya tenían subdivididas las fincas, entre herederos y parientes, aun con una única administración; poseían los bancos que les autoconcedían crédito para la cosecha y se habían diversificado, con lo cual sortearon mejor el impacto. Mientras que los propietarios intermedios conservaron la unidad de la propiedad en cada finca y hacienda, debían los créditos de avío, que no lograron pagar con esa cosecha -la indemnización tardó, no era líquida y estaba por debajo del valor real, ya que se basó en lo declarado al fisco- $y$ en algunos casos no pudieron hacer valer el derecho de reserva.

\subsubsection{La banca y el comercio exterior}

En la banca todo fue más expedito. El Estado se hizo cargo de las acciones, los bienes muebles e inmuebles, los activos y los ahorros de los nueve bancos existentes: los actuales y además los de

16. L. Simon y J. C. Stephens, La reforma agraria en El Salvador (80-81), su impacto en la sociedad, noviembre de 1981 .

17. M. Dolores Albiac, La situación legal de la reforma agraria. Estudio para el Departamento de Economía, Universidad Centroamericana “José Simeón Cañas”, noviembre de 1989.

18. "Visión global...", op. cit.

19. El Salvador. Monografia, op. cit.

20. Entrevista de la autora.

21. M. A. Cuéllar, "Leyes que rigen a las cooperativas de El Salvador", Universidad Centroamericana "José Simeón Cañas", julio de 1988. 
Crédito Popular, Mercantil y Financiero. Tras la intervención, en 1980, había 1274 millones de colones en depósitos y 1 340 millones de colones en créditos ${ }^{22}$. No hay un dato preciso del monto de las reservas ni de los ahorros desaparecidos antes de esta medida, pero la misma fuente, hostil a las reformas, estima en 9 mil millones de dólares el capital que salió del país durante el conflicto.

Hay que sumar los créditos no pagados a la banca estatal por empresarios que se vanagloriaban de no cancelarlos, en una defraudación al Estado, a modo de desquite por las reformas. El control estatal del comercio exterior supuso, durante el conflicto, el principal ingreso del Estado junto a la ayuda militar y económica estadounidense. En especial, el impuesto a la exportación del café, aunque conforme los años pasaron, se generalizó no repatriar las ganancias, una poderosa razón para que algunas familias extendieran sus negocios fuera de la región o acumularan una fortuna en activos en Estados Unidos.

La junta se vino abajo con la represión masiva y la ofensiva guerrillera, que inició la guerra civil, en 1981. Aunque el Estado mantuvo el control de la banca y del comercio externo, la reforma agraria quedó congelada, no se desantolló la fase II. La tres - concesión de pequeñas propiedades a campesinos sin tierra- incluyó 93 mil parcelas, pero sólo el 6.9 por ciento obtuvo título de propiedad definitivo ${ }^{23}$. La puntilla fue la corrupción de las instituciones implicadas y más tarde la regresión - demandas en la Corte Suprema de Justicia contra la reforma agraria-.

Pero no se trata aquí de analizar estas reformas, sólo de reseñarlas, dado que algunos agroexportadores las fustigaron desde el principio hasta hoy, confundiendo el cómo se aplicaron con la bondad, la justeza o la necesidad económica de las mismas. "Ellos no perdieron el poder con las reformas, lo habían perdido antes, en la ingobernabilidad de la dictadura. Las reformas no fueron la causa de su pérdida de poder, sino la conse-

cuencia", señaló uno de los participantes del movimiento. En todo caso, tampoco la izquierda ha revisado todavía ese período ya lejano y vivencialmente próximo.

Con todo, las reformas, unidas a la falta de descendencia, los secuestros, a que las fincas eran escenario de la guerra, etc., desplazaron de los primeros escalones a varias familias tradicionales. Así, los Dueñas, Wright, Daglio, Deinninger, Guirola, Muyshont, Alvarez, Liebes, Escalante y Umaña. El proceso forzó sobre todo a poner a producir la tierra subutilizada y generalizó la tendencia a la diversificación del sector agrícola hacia la industria y el comercio, todo lo cual modernizó la estructura económica, en un sentido que sólo se aprecia en comparación con las vecinas Honduras y Guatemala, que nunca tuvieron reforma agraria y donde todavía hoy una reforma del agro parece subversión.

\section{Los nuevos ricos}

\subsection{Antes de la privatización}

Los Robertos - Llach, Hill, Murray Meza y Mathies Regalado ${ }^{24}$ - constituían los "cuatro Bobys" de la playa quienes, a finales de los ochenta, eran la argolla más pequeña de la élite. Un grupo de amigos con inquietudes comunes, quienes en sus apellidos o por delegación del grupo familiar reunían las mayores fortunas. No integraban un cír-

22. Balances oficiales citados en la ponencia de Gabriel Pilona Araujo. Seminario de privatización de la banca. San Salvador, 1990.

23. "La situación legal", op. cit.

24. Alguna fuente sustituye a Hill por Roberto Daglio. 
culo formal, pero comentaban, consultaban $\longrightarrow 0$ llamaban a consulta - y sugerían los temas que debían estar sobre el tapete de la élite del sector privado $^{25}$. Por eso, aunque había algún otro con rentas similares a las suyas, delegaban sus inquietudes, en parte porque no se exponían a la luz pública o vivían más fuera del país que en él.

En cualquier caso, el ranquín se alteró a finales de los ochenta por la privatización de la banca, ocurrida en $1990^{26}$, y por factores derivados del conflicto, como la acumulación en el sector industrial —debido al abandono del agro durante la guerra- y en el terciario, en particular, en el sector comercial, textil y de comunicaciones. Este último, por el fenómeno migratorio, como la compañía aérea Taca o las de currier (Gigante Express, la filial local de $D H L . .$.$) .$

Cuando Alfredo Cristiani fue designado candidato a la presidencia de la república, era poco conocido más allá del círculo familiar y empresarial, aunque se había fogueado en la Asamblea Legislativa, donde su partido (ARENA) ganó la mayoría en 1987. Contra su escaso liderazgo - recordado con insistencia por el sector más duro del partido- se esgrimía que al ser uno de los grandes empresarios, estaba vacunado contra la corrupción y contra otras tentaciones del ejercicio del poder $^{27}$.

\subsection{La privatizacion de la banca}

La estatización de la banca contempló vender a particulares el 29 por ciento de las acciones de los bancos, lo cual hizo la Junta Monetaria, a partir de 1983. Una parte de las acciones fue vendida a los trabajadores. Los bancos de Crédito Popular y Mercantil fueron absorbidos por medio de fusiones. Varios entrevistados aseguran que, en los últimos años y poco antes de la privatización de la banca, como no había juntas directivas, los directores existentes se quedaron con la mayoría de las acciones al privatizar los bancos. De esta forma, los bancos cambiaron de manos.

\begin{tabular}{lll}
\hline Bancos $^{28}$ & Antes de 1980 & Después de 1989 \\
\hline Salvadoreño & Guirola & Simán \\
Agrícola & Escalante-Sol Millet & Baldochi Dueñas \\
Cuscatlán & Roberto Hill & Samayoa-Cristiani \\
Comercio & Regalado Dueñas & Bellismelis García Prieto \\
Desarrollo & & Salaverria \\
Bancor & & Roberto Hill \\
Bancasa & & Zablah \\
Credisa & & Dutriz \\
Credomatic & & Murray Meza-Pellas \\
Ahorromet & & Poma \\
\hline
\end{tabular}

Aunque estos datos son parciales, a simple vista se observa la recomposición de la élite alrededor de la privatización de la banca. El fenómeno es similar al ocurrido cuando el café y más tarde el algodón y la caña de azúcar sustituyeron al añil. El nuevo esquema financiero se completó con la privatización de los fondos de pensiones, cuyo cuadro se añade en un anexo en este artículo ${ }^{24}$.

25. Este tipo de círculos existen en todos los países; comentan la actualidad, resuelven crisis y a veces también deciden candidatos y créditos para los partidos - lo usual es dar a todos proporcionalmente, según su posibilidad de triunfo y los intereses en juego-.

26. El 6 de diciembre de 1990 se aprobó la "Ley de Saneamiento" por la que el Estado absorbía la mora, y el 12 de ese mismo mes se aprobó la "Ley de la Privatización".

27. La democracia cristiana terminó el período abrumada, entre otras cosas, por una corrupción que, dada la ayuda estadounidense de un millón al día, era la mayor de la historia.

28. Otro banco completa el cuadro, el Banco de Fomento Agropeuario que es, en realidad, estatal; aunque García Prieto imprime un sello personal a su gerencia. A su vez, Credisa fue una financiera hasta que quebró.

29. La nueva arquitectura financiera se completa con las aseguradoras, en manos de los principales banqueros, y, lo más reciente, la creación de los fondos privados de pensiones -denominadas AFP-, cuyos principales accionistas privados también corresponden a los principales bancos; ver el anexo 2 en este artículo. 
Varias medidas fueron clave en este proceso. Una de ellas, de índole indirecta, el establecimiento del cambio fijo y la promoción de mecanismos fiables para captar las remesas familiares - apertura de sucursales de los bancos locales en Estados Unidos- reactivó con rapidez al sector e hizo aumentar las reservas. Entre las medidas directas, el Estado asumió la cuantiosa mora de 2800 millones de colones (unos 400 millones de dólares) ${ }^{30}$, presentada como "saneamiento de la cartera" (ver ejemplo en el anexo). Además, la venta de las acciones no fue muy pública, los trabajadores despedidos fueron presionados para que vendieran sus activos y no se establecieron mecanismos para evitar los testaferros.

Por último, se disolvió la Junta Monetaria, encargada de dictar la política monetaria de una forma más o menos autónoma. La función fue transferrida al recién nombrado director del Banco Central de Reserva (el banco del Estado), Roberto Orellana Milla. Durante la privatización, Orellana Milla compró acciones de varios bancos (Cuscatlán) y financieras, tal como se supo en octubre de 1998, en las casi 48 horas continuas de interpelación parlamentaria, a raíz de la crisis financiera de Finsepro-Insepro ${ }^{31}$.

Un incidente ocurrido en esos meses, previos a la privatización, ilustra los derroteros que tomó hace unos meses la crisis financiera. En esos años, todavía en guerra y desde la fijación del cambio, surgieron instituciones financieras y casas de cambio con poco control. El control fue menor al desaparecer la Junta Monetaria. Asimismo, los créditos personales con poco respaldo y aun los casos de corrupción clara se multiplicaron.
El asunto apareció en documentos del Congreso $^{32}$ y en informes del gobiemo estadounidense, que todavía concedía una cuantiosa ayuda al país. El senador Leaghy tomó muy a pecho el que los fondos de sus contribuyentes fueran despilfarrados por un sistema bancario dirigido por la élite económica local. Tras muchas presiones, Cristiani autorizó las órdenes para capturar a la junta directiva del Banco Agrícola Comercial, por lo que en ese entonces se denominó desfalco.

El director del banco era Roberto Mathies Regalado, quien, como ahora, logró huir a Guatemala antes de ser detenido; pero juró ante propios y extraños que no olvidaría la afrenta. Además, a Mathies Regalado, así como también a algunos otros apellidos rancios, lo dejaron al margen de la privatización de la banca y de algunos negocios que hubo durante el gobierno de Cristiani. Según algunas fuentes, a esta pugna respondía el conglomerado financiero-político y de espionaje que se develó en el escándalo Finsepro-Insepro.

Por el lado financiero, la lista de la docena de inversionistas de Finsepro e Insepro, con más de 50 millones de colones -entre quienes se encuentran connotados dirigentes del partido gobernante, considerados del ala dura-, es ilustrativa. Asimismo, la sorprendente infraestructura de espionaje descubierta en unas habitaciones ocultas, en las instalaciones de la empresa intervenida, Automotriz Sabater $^{33}$, es impresionante.

El diseño, iniciado en 1989 con la estabilización del cambio y la creación de las casas de cambio y las financieras para captar los preciados recursos de las remesas familiares y luego con la

30. Ponencia sobre la privatización, op. cit.

31. En lo inmediato, el gobierno mantuvo a Orellana Milla en el cargo, aunque unos meses después dimitió, alegando asuntos familiares.

32. "Informe de la Comisión de Control de Armamento y Política Exterior", Congreso de Estados Unidos, 1987.

33. Se encontró el registro documental y filmico de políticos, empresarios, funcionarios, periodistas, incluyendo sus números de cuentas, los detalles de sus hijos - como colegios y horarios-, material que, según quienes estuvieron a cargo de la investigación, ha desaparecido. 
privatización de la banca, se completó con la creación reciente de las administradoras de los fondos de pensiones, las cuales, empresas aparte, están todas vinculadas, de un modo u otro, a los principales bancos o a sus accionistas. Estas cierran el círculo del diseño del nuevo sistema financiero. De hecho, el presidente del Banco Central de Reserva, Orellana Milla, no dimitió a causa del escándalo de Finsepro-Insepro, sino justo después de completarse la creación de las administradoras, aunque en su renuncia alegue asuntos privados.

\section{De los "Bobys" a los Alfredos, Ricardos...}

Cristiani Burkard aparecía, a comienzos de los ochenta, con 6 millones en activos de ocho empresas, ocupando uno de los escalones bajos del ranking de la élite. Si bien su madre era la heredera de uno de los grandes beneficios de café, fue más bien su propia gestión administrativa de la fortuna de los Llach - de la que su esposa es una de las tres herederaslo que le posibilitó, en principio, multiplicar sus activos. Los beneficios Burkard y sus fincas y las de los Llach no dejaron de producir durante el conflicto, aun en aquellas zonas que estaban bajo el control del FMLN porque, a diferencia de otros, pagaba impuesto a la guerrilla y salarios aceptables a sus trabajadores ${ }^{34}$. Se diversificó en sectores de rápido crecimiento, en esa época, como los seguros SISA — vinculado al sector finciero y bancario- o los laboratorios - un sector que junto con las farmacias dejaba márgenes de utilidad muy altos-.

A comienzos de los noventa, sus beneficios y los de los Llach estaban en la bolsa de Nueva York. Fue entonces que una de las herederas de la fortuna de los Llach hizo públicas las diferencias familiares por la forma en que estaba siendo administrado el capital. Según todas las fuentes, el salto definitivo lo dio al controlar el Banco Cuscatlán, gracias a la privatización, aunque el ex presidente asegura no poseer más del 3 por ciento de las acciones ${ }^{35}$.

El heredero de los Poma ${ }^{16}$, con activos de tan sólo 35 millones de colones distribuidos en dieciocho empresas, durante los ochenta, hubiera sido uno de los "Bobys" a no ser porque se llama Ricardo y porque su familia no pertenece - tal vez nunca lo pretendió- al círculo de los apellidos rancios. El abuelo fue un mecánico español, que llegó en la primera mitad de siglo, quien se concentró en negocios de rápida acumulación, desvinculados del café y del agro, como los bienes raíces. Al parecer, la acumulación original se dio al comprar a bajo precio terrenos baldíos, situados en áreas de previsible expansión urbana, y esperar a que aumentaran su plusvalía. Después establecieron distribuidoras de vehículos (ahora, DIDEA).

También se les atribuye la propiedad de los terrenos donde luego se construyó el aeropuerto de Miami. Un mecanismo parecido utilizaron en la zona de Metrocentro, Metrosur y en el Boulevard Los Héroes, donde en una parcela todavía se encuentra la oficina central de DIDEA. Fueron los primeros distribuidores de camionetas -Plymund-, de Ford y GM. En los ochenta empezaron a distribuir las marcas japonesas. Fueron también los primeros en incursionar en el turismo y la hostelería, construyendo el Hotel Camino Real y otros dos hoteles en la región - hay tres más en proyecto, en asociación con Intercontinental Hotels-. Ade-

34. Durante la guerra, el FMLN negociaba con los hacendados salarios altos para los trabajadores de las fincas e impuestos por camión de café cortado, y atacaba los beneficios de quienes no negociaban.

35. El ex presidente Cristiani insiste en esta versión en público, pero nadie de ese círculo, de las gremiales del sector privado o de sus adláteres, lo duda y algunos comportamientos alrededor de la crisis financiera de octubre de 1997 lo confirman.

36. Los Poma también tenían un heredero llamado Roberto, quien murió cuando estuvo secuestrado por la gucrrilla, en los ochenta. 
más de expandirse en la región y fuera de ella, desarrollaron industrias relacionadas con sus negocios; invirtieron en construcción (Construcciones Roble y Estructuras Metálicas), en Taca y, últimamente, también en la banca.

Baldochi Dueñas recuperó la decandencia de la fortuna principal de los sesenta. Aunque afectados por la reforma agraria y por una generación perdi$\mathrm{da}$, las haciendas que les quedaron y los derechos de reserva de la gran finca ubicada entre San Salvador y Santa Tecla - "El Espino"-, cuya propiedad disputaron y ganaron en la Corte Suprema de Justicia, les sirvieron para remontar la crisis. La expansión de la capital en esa dirección y la urbanización de la zona de Santa Elena -donde se encuentran la nueva embajada estadounidense y varios edificios para desarrollar actividades empresariales - multiplicó sus activos con rapidez. Antes de absorber la mayoría de las acciones del Banco Agrícola Comercial, ya tenían acciones en Taca.

\subsection{Las minorías étnicas}

La élite salvadoreña fue históricamente poco permeable a incorporaciones "étnicas", hasta el punto de excluir de los mejores colegios privados y de su exclusivo club a judíos y árabes ${ }^{37}$. La migración judía fue mucho más adinerada y reducida que la árabe; buena parte de la misma llegó antes de la segunda guerra. Una de las mayores fortunas es la de la familia De Sola, judíos españoles, emigrados a principios de siglo, a través de Holanda. A diferencia de los Poma, los De Sola se dedicaron a la agroexportación del café, convirtiéndose en uno de los beneficiadores principales pero, al igual que ellos, pronto se diversificaron en industrias alimenticias (aceites, molinos...), con activos hasta en 69 empresas, antes de 1980. En la actualidad, De Sola tiene inversiones en sorbetes (Walls), en centros comerciales - Plaza Merlioty en hostelería - forman parte del consorcio internacional propietario del Hotel Princess-.
Aunque apoyándose entre sí, por mera supervivencia $^{36}$ o por reflejo de la exclusividad de la sociedad local, la comunidad judía constituye todavía un grupo cerrado, que siempre evitó la publicidad y, sobre todo, la política. Sin embargo, en sus alianzas económicas y familiares no operan de esta manera. La mayoría de las familias (Liebes, Gooldtree, Schwarts, Yarhi, Moore, Cohen...) fundó empresas de capital mixto, abiertas a otros accionistas y sus hijos e hojas se casaron fuera del círculo étnico.

Al contrario, la emigración árabe fue numerosa y poco adinerada y aunque abierta en sus relaciones - hasta el punto de disputar su aceptación en las gremiales del sector privado-, hasta esta generación sus hijos e hijas se casaban entre ellos y no hacian negocios con gente que no perteneciera al grupo. Los palestinos cristianos que llegaron a Centroamérica entre las dos guerras mundiales son conocidos, despectivamente, como "turcos", porque llegaron con pasaportes turcos ${ }^{34}$.

De éstos, sólo Simán aparecía antes de 1980 en el selecto primer grupo de adinerados, con activos de 135 millones de colones, en 52 empresas. Sin gran inversión agrícola, los Simán se beneficiaron del rápido crecimiento del comercio, en un principio dirigido a sectores de clase media - almacenes cuyos artículos tenían precios bajos y estaban ubicados en zonas populares-, para pasar después a la cadena de grandes almacenes con sucursales en Guate-

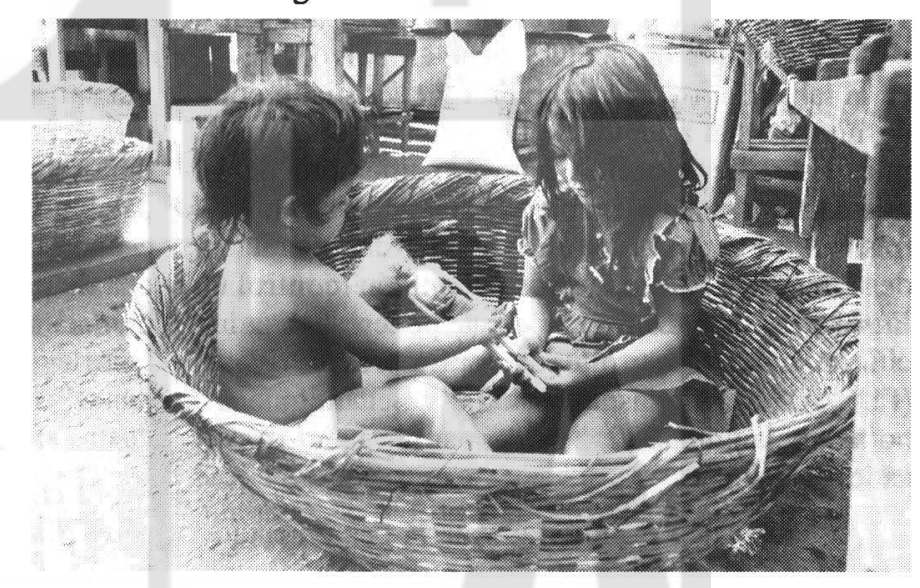

37. Hasta la Constitución de 1983, los negros no podían obtener residencia.

38. A El Salvador también emigraron algunos nazis.

39. El Salvador llegó a prohibir el ingreso de más, una de las razones por las que la comunidad árabe es más numerosa y económicamente más poderosa en Honduras. 
mala y en algunas ciudades estadounidenses, donde exponen productos que el emigrante puede comprar para que les sean entregados a su familia en El Salvador. Al diversificarse, incursionaron en otras actividades, como la construcción y, más recientemente, la banca.

Las otras familias árabes, con activos significativos a comienzos de 1980, aparecían en el último escalón. En la actualidad se encuentran mejor colocadas y ampliaron el círculo a otros apellidos. Así, Safie, que declaraba 24 millones de colones en activos de trece empresas, creció, entre otros, mediante los bienes raíces. Hasbún Handal aparecía con 11 millones de colones, en seis empresas, pero en la actualidad es uno de los directivos de Taca. Saca, con 3 millones de colones, en cinco empresas, se expandió también mediante los bienes raices $\mathrm{y}$, por último, Bahaia, que aparecía con 1.5 millones de colones, en dos empresas.

En los ochenta no figuraban otros que hoy ocupan un lugar importante en esta comunidad y fuera de ella, como los Zablah que, desde su empresa de camas Capri, incursionaron en el sector alimenticio -distribuyeron licores, leche en polvo, etc.-, en la tabacalera y en el gobiemo de Cristiani, donde uno de sus miembros fue Ministro de Economía. Este fue sucedido por otro miembro de la misma familia en el gobierno de Calderón; mientras que el ex ministro dirigió la Administracion de Puertos y Aeropuertos. También controlan Bancasa y la presidencia de la poderosa Fundación para el Desarrollo de la Empresa Privada (FUSADES). Asimismo, Salume y Sedán, quienes no aparecían en 1980 , hoy ocupan un lugar destacado.

Al hablar de las minorías vale la pena mencionar la escasez de mujeres empresarias. Hay alguna que otra excepción en este "feudo de hombres", como Elena Bolaños, quien por décadas ha terciado en la actividad cafetalera, y Vicky Dalton, quién presidió la reducida asociación de beneficiadores. Mercedes Madriz se destacó en solitario en un ambiente donde hasta ahora las mujeres ocupan puestos de dirección, los medios de comunicación. La presencia de las mujeres es más frecuente en el comercio, como son los casos de María de Böet, fundadora de Kismet, y Thelma Davison, presidenta de los Laboratorios López.

En general, la práctica usual hasta ahora ha sido que los maridos, aun sin fortuna propia, representen el negocio pero, si no existe relación sanguínea con alguna "familia", las riendas siguen estando bajo el control de los varones del consorcio familiar y si no los hay, de la esposa, aunque ésta se mantenga en el anonimato doméstico ${ }^{41}$, pero es conocida en los salones y clubes como el poder decisorio.

\subsection{Los otros factores de acumulación}

\subsubsection{El monopolio}

Es sorprendente cómo, en medio del fundamentalismo de la teoría neoliberal y en una estructura económica tan pequeña como la de EI Salvador, sobrevivan prácticas monopólicas sin que la palabra exista siquiera en el vocabulario político y económico en uso. Sólo algún autor se refiere a ella de pasada y algo se empieza a utilizar en relación con la concentración del sistema bancario. Una ley sobre el tema duerme el "sueño de los justos" en la Asamblea Legislativa, desde hace cuatro años.

El caso más espectacular es el de la compañía aérea Taca, cuyo ex presidente E. Borgo fue vicepresidente de la república después y el actual presidente de la compañía, Fidel Chávez, fue la prin-

40. En la mejor tradición, la "familia" que incluye tíos y amigos cercanos de los padres, ejerce una tutela fuerte en el caso de las herederas casadas con hombres sin fortuna, en especial en ausencia del padre o de hermanos varones. 
cipal figura del Partido Demócrata Cristiano y ex ministro. Durante el conflicto regional, las compañías aéreas de los países del área entraron en crisis. La nicaragüense Aeronica y la hondureña SAHSA quebraron; no así la salvadoreña Taca; en gran medida debido a la emigración tolerada hacia Estados Unidos -la quinta parte parte de la población salvadoreña, un millón aproximadamente, reside en territorio estadounidense-. Taca aprovechó la situación para crecer.

Taca International se fundó con capital salvadoreño - Poma y Kriete- y japonés a finales de los ochenta ${ }^{4}$. Taca compró Aeronica y SAHSA y la mayoría de las acciones de la guatemalteca Aviateca, de la cual el gobierno de Guatemala retuvo un tercio. La absorción de la costarricense $L A C S A$ fue más lenta y complicada por la resistencia local. En poco tiempo, la compañía dominó todo el mercado regional y con ello el paso del norte al sur del continente o viceversa pero, además, obtuvo el control absoluto de los precios. Las tarifas no se corresponden con los ranquín internacionales de costo-millas y un tramo tres veces más corto (San Salvador-Miami) cuesta igual que uno intercontinental.

Al terminar el conflicto regional, cuando otras compañías aéreas internacionales quisieron volar sobre el espacio centroamericano, Taca se resistió, pero al final aceptó, condicionando las autorizaciones a mantener elevado el precio. En estas condiciones, comenzaron a aterrizar en San Salvador Aeroméxico, American Airlines e Iberia. La primera de ellas bajó el valor del boleto San Salvador-México de 400 a 300 dólares y la última trasladó su centro de operaciones a Miami para, desde ahí, transportar a sus pasajeros con destino a San Pedro Sula, Cancún, San José, San Salvador y Managua. A Aeroméxico no le renovaron el permiso de vuelo y aterrizaje e Iberia tuvo dificultades hasta que aceptó que en los vuelos intercontinentales, el pasajero pudiera utilizar Taca hasta Miami. American Airlines mantuvo los precios, pero argumentó la reciprocidad, es decir, el derecho que tenía de gozar de los mismos derechos que Taca gozaba en Estados Unidos. Finalmente, hace un año, entró en sociedad con Taca, aunque United Airlines, Continental y Delta recurrieron, sin éxito, al Departamento de Transporte estadounidense, invocando las leyes antimonopolio.

"No es posible que nuestros productores de frutas y flores ingresen en el mercado europeo en 72 horas cuando los ticos o guatemaltecos llegan en 24; no es posible que San Salvador-Miami cueste el doble que desde San José", dijo al respecto el entonces encargado de la privatización, Alfredo Mena Lagos ${ }^{42}$. El asunto de los precios versus los permisos sigue originando disputas con Iberia, la panameña Copa y el gobierno de Costa Rica, a través de su Instituto de Turismo. Por su parte, el vicepresidente Borgo explicó recientemente que el "proteccionismo" del cual TACA gozaba era algo usual en las grandes compañías nacionales. Aunque la línea aérea no es pública, el gobierno no mostró el mismo amor por las grandes compañías estatales como ANTEL. En este último caso, su antiproteccionismo militante es manifiesto.

Un caso de monopolio más rancio es La Constancia, la única fábrica de cervezas y también la única empresa distribuidora de bebidas gaseosas, propiedad de las varias familias Meza. Después de fundar su propia empresa de gaseosas nacionales (La Tropical y La Cascada), tras aliarse con la Coca-Cola para la distribución, ninguna compañía ha podido penetrar el mercado y las anécdotas son pintorescas. Así, cuando la guatemalteca Cerveza Gallo lo intentó, La Constancia empezó a distribuir

41. La composición del capital de Taca International nunca ha sido aclarada. Una fuente confiable del ramo lo confirmó sin querer entrar en montos; señaló el interés del capital asiático en el mercado estadounidense, donde Taca monopoliza buena parte del pasaje centroamericano.

42. "Liberalización, modernización del Estado y privatizaciones". Ponencia de Alfredo Mena Lagos, ex comisionado presidencial para la privatización, en un seminario de Fucad-Konrad Adenauer, julio de 1997. 
sus marcas en Guatemala y afectó tanto el mercado, que el acuerdo entre la familia cervecera guatemalteca - también monopolio- y La Constancia fue fácil ${ }^{43}$.

Antes de la supresión de los aranceles y las restricciones a la importación de cerveza, La Constancia negoció, una a una, con las marcas internacionales más importantes (Guiness, Heineken, etc.) en su empeño por controlar su distribución y evitar la competencia. El monopolio es de tal calibre que, cuando la Asamblea Legislativa discutió las reformas impositivas, que incluían el impuesto a las bebidas alcohólicas, hubo una negociación directa.

Sin duda, el monopolio más grande es el del procesamiento de café. Las veinte y seis familias beneficiadoras son las que fijan el precio de compra del grano. Los pequeños productores e incluso los medianos, una vez iniciada la cosecha -a los dos meses-, no tienen capacidad para almacenarla dadas las condiciones ambientales que requiere-. Esto los obliga a recurrir a los grandes beneficios. No obstante la información disponible sobre las variaciones del precio internacional, los grandes beneficios compran entre $20 \mathrm{y}$ 50 dólares menos el quintal a los medianos y pequeños productores.

El tabaco es un caso similar. La Cigarrería Morazán, aparte de no haber permitido el establecimiento de ninguna otra empresa en el ramo, monopolizó la distribución de la semilla, obligando al mismo tiempo al productor a entregarle toda la cosecha. En cualquieı caso, la empresa emigró a Honduras hace poco.

\subsubsection{El narcotráfico y el lavado}

Es de sobra conocido cómo el tráfico de drogas empezó en Centroamérica para financiar y encubrir la ayuda a "la contra" nicaragüense, y el caso Oliver North sacó a la luz que la base militar de Ilopango fue utilizada como estación de los vuelos que llevaban y traían armas y estupefacientes. El escándalo obligó a Washington a poner fin a estas operaciones; pero, aparentemente, una red siguió operando, aunque ya no para beneficio de los rebeldes nicaragüenses, $o$ al menos no sólo para ellos.

En los primeros meses después de los acuerdos de paz, se denunció la desaparición de dos bombas de $250 \mathrm{k}$ de explosivo de los arsenales del ejército. En principio, el coronel Leiva fue detenido, pero sólo apareció un artefacto. Se informó que las bombas estaban destinadas al, entonces todavía vivo, jefe del "cartel de Cali", Escobar Gaviria, encarcelado en Enviagado, donde serían lanzadas. Nunca más se supo ni de la bomba perdida ni del coronel.

Un reciente informe de la Fundación Heirich Boll ${ }^{44}$ señala que "el negocio" ha contado, desde su inicio, con "un componente militar"; "la gran pregunta para estos países (Guatemala y Honduras) y en cierto modo para El Salvador, es hasta qué punto pueden existir grupos de narcotraficantes, cuyo desarrollo y consolidación pueda ser el punto de amanque de una reversión militarista que devenga en narcodictaduras como ocurriera en Paraguay y Bolivia". Las fuentes aseguran que no es para tanto.

Al principio, sólo unos pocos militares, relacionados con "la contra", se beneficiaron de este tráfico ilícito; pero la actividad se fue extendiendo y muchos otros participaron y obtuvieron pingües ganancias, al menos a juzgar por los elevados ahornos que depositaron en Finsepro-Insepro. El mismo informe señala: "el aumento de las inversiones inmobiliarias y cierta hipertrofia del sistema bancario-financiero, formal e informal, son las señales claras de que en los circuitos económicos de nuestros países, se están introduciendo narcodólares [...] otro tanto cabe decir de la proliferación de centros comerciales y grandes edificios".

43. Recientemente, las cinco familias cerveceras de los cinco países centroamericanos fundaron un consorcio regional.

44. Fundación Heirich Boll, Centroamérica: gobernabilidad y narcotráfico, Guatemala, 1997. 
Sobre este asunto hay nombres y apellidos en danza, pero nadie se atreve a confirmar los detalles. Todas las fuentes aseguran que del grupo militar original, las conexiones con el narcotráfico se extendieron a los civiles $y$, en particular, a algunos empresarios. Mencionados en investigaciones policiales o procesos penales están Safie, propietario de las bodegas en las cuales se encontró un importante alijo de cocaína, y Domonech, encausado judicialmente, en Guatemala, aunque él siempre ha negado este extremo.

"Si eres un accionista o institución con grandes cuentas, recibes una carta que te propone ingresar 21 millones de dólares en una cuenta en Sudáfrica a cambio de ingresarte 30 millones en la tuya aquí", explicó uno de los destinatarios, sorprendido del nivel de infiltración del narcotrafico en los bancos. Tras la crisis financiera en Asia, han aparecido "visitadores", quienes ofrecen dinero muy barato, a través de transacciones con Shangay. Una reciente lista de los principales empresarios implicados en el lavado, elaborada por un organismo internacional, incluye dos docenas de nombres. Hace poco, el entonces direc-

tor de la Policía Nacional Civil, Rodrigo Ávila, reconoció que la estructura de Finsepro e Insepro sirvió para lavar dólares, pero alegó la falta de legislación para poder combatir el fenómeno.

\subsection{A modo de conclusión}

Los cuatro "Bobys" y sus jornadas de playa suponían ya un cambio generacional respecto a la élite tradicional de hacendados, que dominó durante dos tercios del siglo XX. Además de ser personas con mayor educación y que han viajado más, en lugar de ser rentistas eran cabezas de consorcios diversificados. Ya no dirigían a control remoto las fincas de café, como antes. Pero era un grupo que estaba "bajo la tutela" de mentores y familias de una élite muy mezclada con los avata- res políticos e implicada en la guerra sucia de los escuadrones de la muerte ${ }^{45}$, a principios de los ochenta.

En este sentido, el gobiemo de Cristiani y él mismo, ajeno a la clase política tradicional, más joven y formado en Estados Unidos, supuso una transición. Se renovó la dirección de las tres gremiales del sector privado con empresarios, quienes reemplazaron a los empleados de antes, veinte años más jóvenes, formados y relacionados con las finanzas intemacionales. En el nuevo grupo - Cristiani, Ricardo Poma, Archi Baldochi, Ricardo De Sola, Roberto Murray, Ricardo Simán...- ya no existe esa dependencia política. En general, sus integrantes son menos ideológicos y predomina en ellos una visión de futuro que los llevó a apostar por la paz y a ganar tiempo frente a los retos de la privatización. Una actitud distinta de la que predomina entre sus vecinos de $\mathrm{Ni}$ caragua y aun de Guatemala, donde sólo un pequeño grupo de empresarios está convencido de las bondades de una mayor transparencia e institucionalidad, si no por fe democrática, al menos por la rentabilidad de sus negocios.

Incluso Cristiani, quien simpatizaba con su homólogo mexicano Carlos Salinas, fue promovido para "convertir" al parlamentarismo a un ARENA que nació de la guerra sucia y del más virulento anticomunismo, aunque su gobiemo estuvo mediatizado por el sector más duro del partido, en especial tras el asesinato de los jesuitas (1989). A diferencia de su homólogas de Nicaragua y Guatemala, al apostar por la paz, la élite económica participó en el diseño de una transición que encarriló a la derecha y a la izquierda en el parlamentarismo, que redujo el tamaño del ejército y lo regresó a los cuarteles, que eliminó a la guerrilla como fuerza armada y la convirtió en el contrapunto necesario para garantizar la institucionalidad y acelerar la modemización, todo ello sin tocar la economía.

45. Tras el asesinato del arzobispo, Mons. Óscar Arnulfo Romero, en 1980, la bala que lo mató fue subastada en una cena de empresarios y hacendados. 


\section{Algunas características}

\subsection{Una élite cerrada a la penetración extran- jera}

Desde siempre, la élite económica salvadoreña se resistió a la presencia directa de capital extranjero. Sea por el arraigo liberal durante el siglo pasado, sea por la autonomía que le permitía el tipo de producto de acumulación —el añil-, o sea por el desinterés de la United Fruit Company (hoy Chiquita), que concentró sus inversiones en la costa Atlántica, el caso es que El Salvador se libró primero del tipo de explotación colonial de la época del dominio inglés y, más tarde, de los sismos políticos que produjo la bananera en la historia regional.

Con la única salvedad de la Cigarrería $\mathrm{Mo}$ razán, cuyo capital original fue inglés, la ausencia de capital extranjero ha sido una constante ${ }^{46}$. Cuando el modelo desarrollista, sustentado en el mercado común centroamericano, colapsó por la guerra entre El Salvador y Honduras (1969), la dificultad para acceder a un mercado más grande y la imposibilidad de esa válvula de escape para el exceso de población llevó, en los setenta, a negociar la instalación de algunas multinacionales (Texas Instruments) y a que el propio capital se extendiera extranegionalmente y buscara socios extemos ${ }^{47}$.

"Se resisten hasta ahora, sobre todo en el sistema bancario, pero como el caso Finsepro-Insepro demostró, cuando los pequeños bancos recurrieron a socios extemos para sobrevivir la avalancha, ya no pueden impedirlo", señaló un economista ${ }^{48}$. "Están miedosos, a la defensiva ante la globalización y, sobre todo, peleados entre ellos. Así, más que aliarse entre ellos previo a comprometerse con socios externos y consiguir colocarse mejor en el sector, buscan en los socios, continuar la competencia local", acotó un economista, al comentar cómo la mayoría de las alianzas recientes (privatización de las telecomunicaciones y derivados, de la electricidad y de los fondos de pensiones, y expansión del sector hotelero) no adoptan la forma de empresas mixtas, como coinversión. La participación local no es mayoritaria y, a veces, ni siquiera es significativa. "No aplican eso de que si no puedes con tu enemigo: únetele, algo que en la globalización ya hacen sus socios extemos (sector de la computación, automóvil, computación, etc.)".

\subsection{Prácticas desleales}

Algunas peculiaridades del modelo explican, en clave de distorsión, algunos de los cambios mencionados. Además de las prácticas monopólicas, la competencia desleal que propició la guerra, con fenómenos como el contrabando, explica las rápidas ganacias de algunas empresas. Incluso hubo negocios típicos de la guerra, como el relacionado con el sabotaje eléctrico. Cuando el FMLN empezó a sabotear el tendido, los partes de guerra del ejército anotaban una cantidad superior de torres y postes a los que realmente había destruido la guerrilla, porque Estados Unidos proporcionaba la ayuda para reconstruirlos. Hubo un convenio con la empresa que fabricaba las estructuras.

Una práctica más común es la piratería (imitación de marcas, copia de productos sin pago de royalties, etc.), contra la cual la embajada estadounidense ha ejercido gran presión en los últimos años. La embajada logró establecer una legislación que garantiza los derechos de la propiedad intelectual y presiona para que sea aplicada. Asimismo, está muy extendida la práclica conocida como "el menudeo", que consiste en comprar productos de marcas intemacionales - al por mayor- no terminados, acabarlos - una fábrica compraba tornillos de acero a los que les hacía las estrías- o envasarlos aquí —es el caso de los laboratorios de medicamentos- y luego comercializarlos como productos locales.

\subsection{El fantasma de las S.A.}

A lo anterior se suma una característica poco evidente, pero determinante de las dificultades de la competencia o aun de las alianzas con socios ex-

46 No obstante, Dada subraya el rezago tecnológico que conllevó en su tesis: "La economía de El Salvador y la integración centroamericana 1945-60". Universidad de El Salvador.

47. Del 59 por ciento de la inversión extranjera en Costa Rica, El Salvador se encuentra en el lado opuesto dentro la clasificación regional con sólo el 4 por ciento, scgún datos del Banco Interamericano de Desarrollo.

48. Bancasa debió asociarse al Scotish Banck, Ahorromet podría hacerlo con un grupo español y el Banco Cuscatlán amplió sus acuerdos con el City Bank. 
tranjeros. Las principales empresas son familiares o son "la familia", en el estilo más antiguo del término. Es decir, salvo en las empresas administradas por una parte del capital (el grupo judío, algunos empresarios visionarios, etc.), las sociedades anónimas son más de nombre que de realidad y el capital no está abierto a socios medianos y menos a los pequeños.

La confirmación más clara de esto es la bolsa, donde se cotizan casi sólo "reportos" - empréstitos para obtener liquidez rápidamente, que no suponen propiedad alguna sobre el capital-. Sólo la empresa Shwarchz ha sacado a cotización títulos de esta clase. Otro ejemplo es la banca. A diferencia de lo que ya es general en casi todos los sectores de los países desarrollados, donde la o las familias con mayor número de acciones no participan directamente en la gestión de las empresas, ni figuran en sus juntas directivas, sino esto está a cargo de técnicos contratados por los accionistas - medianos también-, aquí es "la familia" la que decide incluso sobre los asuntos más ínfimos de la empresa.

\subsection{Las peculiaridades más graves}

La característica sin duda más dañina para el interés nacional es el tradicional carácter sobreexplotador de la mano de obra de este modelo y su carácter "expulsor" de población. Ya en los estudios de los setenta y luego también en los de los ochenta, todos los economistas insistían en la poca alteración de los salarios - aun en tiempos de bonanza o crecimiento- como un factor explosivo que, además, mantenía una gran presión sobre los recursos naturales, dado que la mayoría de los hogares requería ingresos extras, incluso para reproducir su fuerza de trabajo.

Además, como la inversión social fue decreciendo en las últimas dos décadas, todo ello abundó en un deterioro de las condiciones mínimas de sobreviviencia, por lo que si algunos análisis hablan de "una década perdida", en cuanto al desarrollo social, los niveles actuales se comparan a los de los setenta. Aun en estos años con índices macroeconómicos estables, sólo en el último el crecimiento económico superó al de la población.

Otra de las características es la falta de una política oficial y la despreocupación de las élites por el tremendo problema poblacional del pais. Más allá de alentar la emigración, primero a Honduras y luego a Estados Unidos ${ }^{49}$, no han existido medidas específicas para revertir el fenómeno de la densidad poblacional. La única campaña masiva contra el sida, emprendida desde un organismo social, por la esposa del ex presidente Cristiani, fue suspendida por presiones de la Iglesia católica y nunca se reactivó, pese a las alarmantes tasas de crecimiento de esta pandemia.

Incluso, cuando hace unos cinco años se propició la maquila, no fue tanto por ser un sector que absorbía en gran medida mano de obra, si no, más bien, por la rápida acumulación que permite. Igual despreocupación hay por la sobreexplotación de los recursos que la conservación de este modelo implica, en un país con escasos 21 mil kilómetros cuadrados y con la tasa de deforestación más alta del continente, después de Haití. Un ejemplo fue la nueva ley de conservación, concebida más para acallar la presión internacional que por el interés en resolver el grave problema que aqueja al país. La ley permaneció engavetada dos años en la Asamblea Legislativa, por la resistencia de la empresa privada.

\subsection{Otras características}

Otros aspectos del modelo y de la élite tienen un sentido más positivo. La versatilidad para adaptarse a las diferentes condiciones que los llevaron a diversificar y expandir sus operaciones fuera del país muy pronto. Asimismo, cabe mencionar su resistencia durante el conflicto armado, pues bastantes empresas se mantuvieron abiertas pese a las dificultades. Por ello y porque un pequeño sector de la élite apostó decididamente por la solución negociada del conflicto, lograron que el sistema económico saliera intacto de los acuerdos de paz. En ese sentido, para la mayoría o no hubo "retomo" al pasado o el cambio no fue traumático, a diferencia de lo ocurrido en Nicaragua.

Hay que resaltar cómo algunas empresas, sin caer en prácticas desleales, se adaptaron rápido a las nuevas condiciones y aun en medio del conflicto crecieron hasta hacerse transnacionales como Hilasal (propiedad de la familia Sagrera, con planta en México), $A D O C$ (con plantas en Honduras y Bolivia), la papelera SIGMA (propie-

49. El jesuita y director del Instituto de Derechos Humanos de la UCA, Segundo Montes, reveló en una entrevista cómo, desde la base militar de llopango, salían aviones repletos de emigrantes hacia Houston. 
dad de la familia Yarci y con operaciones regionales) y Gigante Express (cuyo consorcio de currier y comunicación por satélite ya aparece en la lista de Forbes).

También, y a diferencia de sus vecinas de Honduras y Guatemala, la élite salvadoreña, aunque encomendó al ejército controlar los estallidos sociales y abortar la revolución, mantuvo a los militares fuera de los negocios ${ }^{30}$. Sólo al final del conflicto $y$, precisamente, con el empresario Cristiani en el ejecutivo, la cúpula del ejército aceptó retirarse a cambio de abultadas compensaciones $^{51}$.

A diferencia de lo que sucede en México y Guatemala, el Opus Dei ${ }^{52}$, en cuanto componente religioso-económico, no es muy significativo, pero sí lo son las iglesias evangelistas estadounidenses, auspiciadas por familias como los Poma. No hay que olvidar que la nueva generación empresarial creció y estudió en Estados Unidos.

\subsection{Dónde está la concentración}

Hay poca información sobre la concentración del ingreso. Los registros empresariales y las declaraciones de renta están desactualizados; en parte, debido al caos que supuso el conflicto y los cambios de la transición y del ajuste, pero también por un deliberado interés oficial poco transparente, al menos por lo que toca a los estudios y análisis de este fenómeno económico, desde 1994.

Según los últimos datos disponibles sobre el ingreso de la Encuesta de hogares ${ }^{53}$, la estructura económica de la población es como sigue:

Los pobres, con ingresos inferiores a $3 \mathrm{mil} \mathrm{co-}$ lones (350 dólares), siguen representando el 62 por ciento de la población, 754 mil hogares
(3,7 millones de personas aproximadamente). Aunque sólo 5 de los 100 estratos (percentiles) cobran menos del salario mínimo (1 260 colones $=144$ dólares), representan el 21 por ciento de la población en extrema pobreza.

La clase media, con ingresos entre 3 y 14.3 mil colones (350 a 1640 dólares), representa el 31 por ciento de la población, 384 mil hogares y los 59 estratos intermedios, aunque la dispersión o estratificación en ese nivel es, en apariencia, mayor que antes, ya que dos tercios se encuentran en el rango de ingreso inferior a los mil dólares

La clase alta, con ingresos que van desde los 15 hasta los 71 mil (1 725 a 8000 dólares), representa sólo el 1 por ciento de la población, 12379 hogares, pero absorbe el 10 por ciento del ingreso, un promedio de 140000 colones (16 000 dólares). De ellos, sólo 518 familias, el ranquín más alto, obtienen el doble que el percentil inmediatamente inferior y esos 71000 colones (8 000 dólares). El ingreso promedio es 204 veces más que el del estrato menor y 20 veces más que el del 62 por ciento de los hogares pobres.

\subsection{Ajenos a la redistribución y el interés na- cional}

Cuando el presidente Duarte quiso establecer un impuesto de guerra y el reclutamiento obligatorio, la empresa privada convocó al paro más efectivo de toda la historia salvadoreña. Las emisoras de televisión y hasta los grandes hoteles pararon y quienes no lo hicieron, pagaron un precio alto. Además de pagar la guerra, la ayuda estadounidense cubría el elevado déficit fiscal (entre 100 y

50. Si bien durante el conflicto varios militares participaron en diversos "negocios" de guerra, en El Salvador, el ejército no llegó nunca a formar parte de la élite económica, ni a poseer bancos o consorcios empresariales como en Guatemala y Honduras.

51. Los quince miembros de la generación denominada "La Tandona", recibieron compensaciones millonarias por su salida del ejército, después de resistir tres años, primero a la depuración y luego a las recomendaciones de la Comisión de la Verdad, que asegura que catorce de ellos tomaron parte en la decisión o el encubrimicnto del asesinato de los jesuitas.

52. Corriente católica fundamentalista, con presupuestos económicos determinantes, fundada en la España franquista por el sacerdote José María Escribá Albás (aunque después se cambió el nombre a Josemaría Escribá de Balaguer).

53. El Estado encarga anualmente una encuesta de hogares, que es la fuente más confiable o cercana a la realidad de que se dispone. 
200 millones de dólares anuales), hasta el punto de que existían dos presupuestos ${ }^{54}$. Durante varios años, el presupuesto público fue menor que la ayuda directa e indirecta de Estados Unidos ${ }^{55}$. El gobierno pidió un mayor esfuerzo, pero la oposición frontal del sector privado a un nuevo impuesto y a que sus hijos fueran reclutados, abortó todo intento para que este sector contribuyera al esfuerzo bélico.

En otro plano, la actitud es la misma respecto a la redistribución. Aunque la función social de la tributación se definió en 1915 y la Constitución de 1950 estableció los fundamentos del sistema fiscal actual, en una "primavera" democrática, la evasión ha sido una constante, incomparable con la usual renuencia a tributar. Es decir, el concepto básico de que una parte de la plusvalía se obtiene gracias a un esfuerzo nacional —del Estado que invierte en infraestructura, servicios básicos, etc., y del trabajo que necesita reproducir su fuerza - parece no ser aceptado, mucho menos que el Estado moderno - de bienestar social- deba cumplir una cierta función redistributiva.

Tal vez el ejemplo más ilustrativo lo constituyan las formas semifeudales de relación laboral, lo mucho que costó desterrar la práctica de pagar en especies (hacia mitad del siglo $X X$ ) o que en las fincas y haciendas se pagara en moneda de la familia propietaria, sólo reconocida en una especie de economato también propiedad de la misma familia (donde el trabajador ya había empeñado su sueldo mucho antes de cobrarlo). En otro plano, pero en la misma línea, está la oposición frontal de la élite al primer intento de la Iglesia católica por alfabetizar (una razón por la cual muchos sacerdotes, religiosas y agentes de pastoral fueron asesinados, antes de que la guerra diera comienzo).

"Después [de 1960], los efectos redistributivos se diluyen con la concesión generalizada de beneficios y exenciones para estimular la producción. La tercera etapa comienza en los ochenta y culmina al aceptarse -obligadamente, al menos en el tercer mundo - la creencia de que la justicia social está siendo sustituida por el propósito del desarrollo económico ${ }^{56 "}$, describe un especialista. Aunque organismos como el Banco Interamericano de Desarrollo apoyan una tibia modemización tributaria, no hubo reforma fiscal en la postgue$\pi^{5}{ }^{57}$ y el esfuerzo actual se limita a aumentar una recaudación (el universo de contribuyentes y la eficiencia recaudadora) que recae más sobre los salarios que sobre la renta.

Así, el impuesto sobre la renta representa menos del 30 por ciento del total de la recaudación fiscal (poco más de la aportación de los emigrantes) con una variación positiva de sólo el 7 por ciento (de 1996 a 1997 contra el 33 por ciento de variación en las transferencias), mientras que la recaudación indirecta, el impuesto al valor agregado, representa el 60 por ciento ${ }^{58}$. No están claras las razones políticas, culturales o sociológicas de esta constante de eludir la redistribución. Un factor, sin duda im-

54. El entonces Ministro de Planificación, Fidel Chávez Mena, confirmó este extremo a esta corresponsal, aunque el presupuesto de la guerra siguió, hasta el final del conflicto, sicndo sccreto de Estado.

55. “Informe de la Comisión...", op. cit.

56. Álvaro Magaña, “El fin de la distribución?”. Revista de Derecho de la Facultad, 2 (1995). Universidad de El Salvador.

57. "La calendarización apresurada de la baja de los impuestos de importación a la que obligaron, provocó un aumento en el consumo más acelerado aún, en un país con lantas necesidades insatisfechas, cuando superar esas limitaciones fue facilitado por el desarrollo de las tarjetas de crédito que produjo un consumismo de la clase media, sin margen de ahorro, agravado irónicamente por las tasas de interés. ¿Cúal es el resultado? Ahí están los mil millones de dólares del déficil de la balanza comercial que no sentimos gracias a las remesas familiares", señala A. Magaña en su artículo sobre la concesión del Premio Nobel de Economía, 1995, a su colega Robert E. Lucas. "El economista". Colegio de Economistas de El Salvador.

58. Dirección General de Tesorería. Ministerio de Hacienda, publicado por La Prensa Gráfica. 
portante, es la costumbre de esta élite a obtener márgenes de beneficios elevadísimos, sin correspondencia ya con la media internacional.

"Invertir en el hombre y combatir la pobreza se reconoce ya como una necesidad en el discurso, pero faltan las consecuencias prácticas", señaló el obispo auxiliar de la capital, Gregorio Rosa Chávez, al considerar que ésta era la clave del éxito del recién elaborado plan de nación para promover el consenso sobre el desarrollo sostenible, la gran asignatura pendiente de este país, en la postguerra, porque, añadió, "no hay ilusión en la paz y demasiada gente se pregunta para qué sirvió, pues aunque la situación cambió radicalmente, la población no lo percibe".

El también sacerdote y economista Javier Ibisate añade: "No hay pobreza estructural sin riqueza estructural". Esto vincula el combate de la extrema pobreza con la reducción de la concentración y la promoción de la redistribución. De otra manera lo dicen incluso el Fondo Monetario Internacional y el Banco Mundial -en recientes visitas-y el economista Michael Porter ${ }^{54}$, quien dijo a los propios empresarios: "Antes la gente tenía éxito porque aprovechaba ciertas oportunidades que se le presentaban: nacía en la familia correcta o heredaba tierras; pero estas fórmulas ya no son válidas. Ahora, la única forma es ser productivos".

"El desarrollo humano es el fin y el crecimiento económico, un medio para alcanzarlo. El próposito principal del crecimiento económico debería ser enriquecer la vida de las personas. Desgraciadamente, esto no sucede con frecuencia. Las décadas recientes muestran claramente que no existe vínculo automático entre el crecimiento económico y el desarrollo humano. Aun cuando estos vínculos logran establecerse, pueden gradualmente erosionarse si no se refuerzan regularmente con políticas públicas inteligentes y bien dirigidas", concluye el informe anual sobre el desarrollo humano de Naciones Unidas ${ }^{60}$.

\section{Anexo 1: privatización de la banca}

El saneamiento de los bancos se realizó por permutas entre FOSAFI y las entidades sujetas a la privatización, por medio de bonos a 10 años plazo y con intereses del 10 por ciento anual. Estos bonos se permutaron por préstamos malos y otros activos. El caso del Banco Salvadoreño es un ejemplo. Se emplearon 1.41 millones de colones a diez años plazo y al 10 por ciento de interés anual, a cambio de créditos y otros activos prácticamente incobrables.

El mismo día que se firmó la escritura de la permuta, el banco se deshizo de los incobrables y comenzó a recibir 114700000 de intereses anuales sobre los bonos. También pudo contabilizar 114700000 colones por el primer año de amortización. En el primer año percibió un ingreso de 229400000 colones sin costo alguno de administración. Una vez saneado, el banco constituyó su capital que ascendió a 106 millones de colones. La venta de acciones se llevó a cabo con las siguientes facilidades cerditicias: la mayoría a un promedio del 15 por ciento como prima a diez años de plazo y el 14 por ciento de interés anual.

En realidad, ni la prima ni las amortizaciones han salido nunca de los bolsillos de los inversionistas porque, por acciones no pagadas totalmente, se han repartido dividendos por cantidades que superan varias veces la cuota de amortización. El accionista debe pagar a FOSAFI el 10 por ciento de las acciones como capital, más los intereses del 10 por ciento anual, y el FOSAFI le pagó al banco 190 millones de capital e intereses, durante el primer año. En los siguientes nueve años, se pagarán cantidades decrecientes de amortización de capital e intereses sobre saldos.

De acuerdo al propio FOSAFI, aportó al banco en bonos:

-Préstamos malos.... 954 millones

-Otros activos..... $\quad 87$ millones

-Aporte de capital.. 106 millones

Total

1147 millones

Por estos 1147 millones de colones, el FOSAFI está pagando 114140000 colones de intereses anualmente; y durante el primer año, 114140000 de amortización. A cambio de más de 220 millones de colones durante el primer año y cantidades

59. Graduado de Harvard que asesora los ajustes en Centroamérica.

60. Naciones Unidas, Informe de desarollo humano 1996. 
decrecientes en los restantes nueve, FOSAFI recibe, por la venta de las acciones, 5300000 de interés y 5300000 por amortización, el primer año. Esta cantidad va disminuyendo gradualmente en los nueve siguientes. Haciendo el cálculo de esos años restantes, resulta que el FOSAFI entrega al banco la suma de 1782 millones de colones en efec- tivo en diez años y está recibiendo 159500000 colones, es decir, FOSAFI paga más de once veces de lo que recibe del Banco Salvadoreño.

(Nota: la fuente se obtuvo de una copia resumida de un documento anónimo, distribuido al comienzo de la privatización de la compañía telefónica.)

Anexo 2: fondos de pensiones

\begin{tabular}{|c|c|c|c|}
\hline Empresas & Socios locales & Bancos respaldo & Socios extemos \\
\hline Porvenir & \multirow[t]{2}{*}{ Dueñas, García Prieto, Zablah } & Provida & \multirow{3}{*}{$\begin{array}{l}\text { Internacional, Chile } \\
\text { Argentaria, España; } \\
\text { Magister, Chile }\end{array}$} \\
\hline Máxima & & Banco de Comercio & \\
\hline Confía & $\begin{array}{l}\text { Sagrera, Murray, Samayoa, } \\
\text { Kriete }\end{array}$ & $\begin{array}{l}\text { Banco Agrícola, Cuscatlán, } \\
\text { City Bank }\end{array}$ & \\
\hline Previsión & Cohen & $\begin{array}{l}\text { Banco Salvadoreño, } \\
\text { Previsora }\end{array}$ & \multirow{2}{*}{$\begin{array}{l}\text { BBV, España } \\
\text { Canada Regal } \\
\text { Capital planers }\end{array}$} \\
\hline Profuturo & \multicolumn{2}{|c|}{$\begin{array}{l}\text { empresas locales de construcción: } \\
\text { DSC, Barrientos Arquitectos, } \\
\text { Avance Ingenieros, Samuer }\end{array}$} & \\
\hline
\end{tabular}

Los consignados como socios locales son quienes aparecieron en la documentación presentada cuando se legalizaron las empresas, aunque corresponden a los accionistas mayoritarios de los principales bancos, en la documentación no figura como propiedad institucional.

\section{Bibliografia}

\section{Entrevistas (por orden alfabético)}

Dada Hirezi, Héctor. Ministro de Economía en la Junta Revolucionaria de 1979. Actual director local de la Facultad Latinoamericana de Ciencias Sociales (FLACSO) y miembro del consejo muncipal de la alcaldía capitalina. Graduado de la Universidad Nacional de El Salvador.

Goitia, Alfonso. Graduado de economía de la UCA. Ex director de su Departamento de Economía y de la FUNDE. Actual Secretario de Concertación Centroamericana de Organismos de Desarrollo.

Ibisate Francisco, Javier. Decano de la Facultad de Economía de la Universidad Centroamericana "José Simeón Cañas" (UCA). Ex rector. Director de la Revista Realidad Económica. Graduado de economía en la Universidad de Lovaina.

Magaña, Alvaro. Presidente de 1982 a 1984. Representante de El Salvador en la negociación del mercacomún y del Acuerdo Internacional del Café. Graduado de derecho en la Universidad Nacional de El Salvador y de economía en Chigago.

Montoya, Aquiles. Profesor de economía de la Universidad Centroamericana "José Simeón Cañas" y graduado en esa universidad.

Rosa Chávez, Gregorio. Obispo auxiliar de San Salvador. Graduado en periodismo, en Lovaina.

Vergara, Luis. Representante en El Salvador del Banco Interamericano de Desarrollo (BID).

\section{Documentos}

Albiac, M. Dolores. "La situación legal de la reforma agraria". Estudio para el Departamento de Economía, Universidad Centroamericana "José Simeón Cañas", noviembre, 1989.

Araujo, Gabriel Pilona. "Ponencia sobre la privatización de la banca", septiembre, 1990.

Censo agropecuario, 1971. 
Colindres, Eduardo. Fundamentos económicos de la burguesía salvadoreña. San Salvador: UCA Editores, 1977.

Congreso de Estados Unidos. "Informe de la Comisión de Control de Armamento y Política Exterior", 1997.

Dalton, Roque. El Salvador. Monografía. San Salvador: UCA Editores, 1989.

Fundación Heirich Böll. Centroamérica: gobernabilidad y narcotráfico, Guatemala, 1997.

Magaña, Álvaro. “¿El fin de la redistribución?”. Revista de la Facultad de Derecho 2 (1995). Universidad de El Salvador.

Ministerio de Hacienda. "Cuadro sobre recaudación de los impuestos". Dirección General de Tesorería. La Prensa Gráfica, 1998.

Ministerio de Hacienda. Encuesta de hogares 1996. Dirección General de Estadística de El Salvador.

Programa de Naciones Unidas para el Desarrollo (PNUD). Informe de desarrollo humano 1996.

Sevilla, Manuel. "Visión global sobre la concentración económica en El Salvador", Boletín de Ciencias Económicas, 3 (1984).

Simon, L. Y Stephens, J.C. La reforma agraria en El Salvador (80-81), su impacto en la sociedad, noviembre, 1981.

Universidad Nacional. La economía en El Salvador y la integración centroamericana, 1945-60. 